\title{
3.8 Million blinded by cataract each year: projections from the first epidemiological study of incidence of cataract blindness in India
}

\author{
D C Minassian, V Mehra
}

\begin{abstract}
Data from a population based longitudinal study of randomly selected communities in Central India have for the first time provided direct estimates of age specific incidence of blindness from cataract. Person-time denominators have been used to compute age specific incidence rates (risk) of blindness from cataract for populations aged 35 and older. These age specific incidence measures have been applied to the 'population at risk' in each 5-year age class in order to estimate the total number of new cases of cataract blindness that occur in the country each year. The findings indicate that an estimated 3.8 million persons become blind from cataract each year in India (approximate 95\% confidence limits: 3 to 4.5 million). The reasons why the estimates are considered as minima, and their implications concerning future national planning of ophthalmic services, are briefly discussed.
\end{abstract}

During the past decade a number of crosssectional surveys have provided data on prevalence (existing cases) of cataract and of blindness due to cataract in various parts of the world..$^{1-5}$ These data indicate that cataract is by far the commonest cause of blindness and visual disability worldwide. However, these prevalence data provide useful information on only the backlog of the cataract problem and do not give information on the number of new cases that occur each year. The latter incidence information is an important prerequisite to rational longterm planning of basic ophthalmic services on a regional or national scale. This paper reports the findings of the first population based longitudinal study which was designed to provide a direct measure of incidence (new cases) of cataract blindness and to evaluate certain risk factors.

\section{Material and methods}

International Centre for Eye Health (ICEH), Institute of

Ophthalmology,

University of London,

27-29 Cayton Street

London EC1V 9EJ

DC Minassian

Chattisgarh Eye

Hospitals, Fafadih,

Raipur, MP India

Raipur,

Correspondence to:

Correspondence to
Dr D C Minassian.

Accepted for publication

16 January 1990
The collaborative study was started in 1982 and was conducted in the Arang Block of Raipur District in Central India. The baseline data were collected from a random sample of 19 communities in the Arang Block (population c.100 000). The sample included 1735 persons aged 30 and older. These constituted the study cohort. Examinations and interviews were carried out by an ophthalmologist and an ophthalmic epidemiologist with the help of three specially trained ophthalmic assistants, using standardised methods. A third independent consulting ophthalmologist was employed to evaluate the field work during the study.
Visual acuity was measured with a standard Snellen's $\mathrm{E}$ chart at $6 \mathrm{~m}$ in shaded daylight. Cataracts (central lens opacities) were identified and graded according to a simple method that has been shown to have excellent interobserver agreement. ${ }^{6}$ The principal cause of any visual impairment below 6/12 was determined, with particular care to distinguish between cataract and other disorders as the main causes. Subsequently, in 1986, the people in the study sample were located, examined, and interviewed by the same standardised methods.

The data were entered into a specially designed relational database by means of a microcomputer and were subsequently analysed with software developed at ICEH in London. The exact period of follow-up was computed for each person so that precise person-time denominators could be calculated. The follow-up times for those who died before the final examination were estimated by ascertaining the time of death through interviews with the family. To ensure that the incidences would not be overestimated, persons who could not be re-examined at the follow-up visit were considered to have been followed up and not to have gone blind from cataract. Furthermore, in computing the number of new cases of cataract blindness, persons younger than 35 in the population were considered to have a minimal incidence, which was taken as zero, because none of these young people became blind from cataract. Infants and children becoming blind from congenital cataract were not included in the projected estimates.

Incidence rates with person-time denominators were computed for each 5-year age stratum. The age specific incidence rates were then applied to the age stratified 'at risk' population of the study area and also of the whole country to arrive at the number of new cases of cataract blindness that occur per year. In addition the 1-year cumulative incidence for each age stratum was derived from the incidence rate of the stratum by the density method. ${ }^{7}$ The equation used was: $\mathrm{CI}=1-\mathrm{e}^{-\mathrm{R}_{t}}$ where $\mathrm{CI}$ is the cumulative incidence in time $t$ ( $t$ being taken as 1 year), $R$ is the incidence rate per year), and $e$ is the constant $2 \cdot 71828$, the base of natural logarithms. Unlike the incidence rate, the cumulative incidence is not a rate but a proportion, and may be expressed as an absolute number, or a percentage of the original cohort, who became cases in a specified time period. The incidence rate on the other hand measures the average speed of occurrence of new cases, and it may be interpreted as the average number of new cases that have occurred per unit of time during the study period. 
The age specific cumulative incidence proportions were also used to estimate the number of new cases that occur in one year in the country.

The age stratified population for India was based on the United Nations publication ST/ ESA/SER.R 170. The population 'at risk' were determined by excluding from the whole population those who were already blind or had had cataract surgery. The expected numbers of these prevalent cases were provided by our crosssectional survey at the beginning of the study.

An incident case was defined as a person who was not blind at the beginning of the study but became blind (according to the WHO categories $3,4,5$ : vision less than $3 / 60$ in both eyes) because of cataract by the end of the study.

\section{Results}

There were 1735 persons aged 30 and older in the sample. Of these, a cohort of 1655 persons were at risk of becoming blind during the study. The remainder were either already blind or had had cataract surgery. During the follow-up period $6 \%$ of the study cohort died.

The incidence rate of cataract blindness in the at risk cohort was 0.0019 per person-year for the age group 35-39 and 0.0581 per person-year for the age group 65 and older. The corresponding annual cumulative incidences were $0 \cdot 19 \%$ and $5.64 \%$. The estimated number of new cases of cataract blindness which occur in the sampled population of Arang was 470 new cases per year per 100000 persons at risk. The projected estimate for the whole country was 3811185 new cases of cataract blindness per year, with approximate $95 \%$ confidence limits of 3 to 4.5 million. The details are shown in Table I. The estimate derived from the cumulative incidence

TABLE I Incidence of blindness from cataract in India. Projections from a population based follow-up study in Central India

\begin{tabular}{|c|c|c|c|c|}
\hline Age & Population * & $\begin{array}{l}\text { Population } \\
\text { at risk }\end{array}$ & $\begin{array}{l}\text { Incidence } \\
\text { rate/person- } \\
\text { year }\end{array}$ & $\begin{array}{l}\text { Projected number } \\
\text { of new cases of } \\
\text { cataract blindness } \\
\text { per year }\end{array}$ \\
\hline $\begin{array}{l}0-34 \\
35-39 \\
40-44 \\
45-49 \\
50-54 \\
55-59 \\
60-64 \\
65+ \\
\text { Totals }\end{array}$ & $\begin{array}{r}579810000 \\
50376000 \\
41665000 \\
35783000 \\
31654000 \\
27369000 \\
22088000 \\
38407000 \\
827152000\end{array}$ & $\begin{array}{r}576197477 \\
50205811 \\
41301114 \\
35203518 \\
29867081 \\
25138933 \\
18182195 \\
29660851 \\
805756980\end{array}$ & $\begin{array}{l}0.00+ \\
0.00190 \\
0.00253 \\
0.00595 \\
0.01336 \\
0.02388 \\
0.03734 \\
0.05810\end{array}$ & $\begin{array}{r}0 \dagger \\
95486 \\
104473 \\
209610 \\
399157 \\
600218 \\
678842 \\
1723399 \\
3811185 \ddagger\end{array}$ \\
\hline
\end{tabular}

^Population of India: based on United Nations publication ST/ ESA/SER.R 170. +Very low incidence in the population; taken as zero, since no incident cases occurred in the sample.

$\ddagger$ Approximate $95 \%$ confidence limits $=3$ to 4.5 million.

TABLE II Age and sex distribution of the study sample and age specific follow-up times in person-years

\begin{tabular}{|c|c|c|c|c|c|c|c|}
\hline \multirow[b]{2}{*}{ Age } & \multicolumn{2}{|c|}{ Males } & \multicolumn{2}{|c|}{ Females } & \multicolumn{2}{|c|}{ Males +females } & \multirow{2}{*}{$\begin{array}{l}\text { Person-years } \\
\text { follow-up }\end{array}$} \\
\hline & No. & $\%$ & No. & $\%$ & No. & $\%$ & \\
\hline $\begin{array}{l}30-34 \\
35-39 \\
40-44 \\
45-49 \\
50-54 \\
55-59 \\
60-64 \\
65+ \\
\text { Totals }\end{array}$ & $\begin{array}{r}124 \\
110 \\
120 \\
134 \\
98 \\
68 \\
77 \\
48 \\
779\end{array}$ & $\begin{array}{r}15 \cdot 92 \% \\
14 \cdot 12 \% \\
15 \cdot 40 \% \\
17 \cdot 20 \% \\
12 \cdot 58 \% \\
8 \cdot 73 \% \\
9 \cdot 88 \% \\
6 \cdot 16 \% \\
100 \cdot 00 \%\end{array}$ & $\begin{array}{r}191 \\
186 \\
109 \\
113 \\
150 \\
67 \\
87 \\
53 \\
956\end{array}$ & $\begin{array}{r}19 \cdot 98 \% \\
19 \cdot 46 \% \\
11 \cdot 40 \% \\
11 \cdot 82 \% \\
15 \cdot 69 \% \\
7.01 \% \\
9 \cdot 10 \% \\
5 \cdot 54 \% \\
100 \cdot 00 \%\end{array}$ & $\begin{array}{r}315 \\
296 \\
229 \\
247 \\
248 \\
135 \\
164 \\
101 \\
1735\end{array}$ & $\begin{array}{r}18 \cdot 16 \% \\
17 \cdot 06 \% \\
13 \cdot 20 \% \\
14 \cdot 24 \% \\
14 \cdot 29 \% \\
7 \cdot 78 \% \\
9 \cdot 45 \% \\
5 \cdot 82 \% \\
100 \cdot 00 \%\end{array}$ & $\begin{array}{r}1123 \cdot 92 \\
1055 \cdot 58 \\
797 \cdot 66 \\
854 \cdot 16 \\
867 \cdot 33 \\
455 \cdot 24 \\
541 \cdot 99 \\
329 \cdot 16 \\
6025 \cdot 04\end{array}$ \\
\hline
\end{tabular}

was 3738947 new cases in one year. This amounts to $0.46 \%$ of the population at risk.

About $0.6 \%$ of the original cohort of 315 persons aged 30-34 developed cataract in at least one eye during the study. However, none of these were blinded by cataract in the sample, reflecting a very low incidence rate of cataract blindness in this stratum of young people. The age and sex distribution of the study sample, together with the follow-up times in personyears, are shown in Table II.

\section{Discussion}

The projected numbers of new cases of blindness from cataract should be considered as minimal estimates because of the following considerations. First, since there were no incident cases of cataract blindness in the youngest age cohort in the sample (younger than 35), the incidence in that population stratum was considered to be very small and was taken as zero. Secondly, persons who could not be examined at the end of the study were included in the denominators and were counted as non-cases. This was mostly justified because by far the commonest reason for being absent at the time of the second survey was new employment. These persons were not likely to be blind. In this follow-up study $80 \cdot 2 \%$ of the original cohort were successfully located again and re-examined (if alive) at the end of the follow-up period. Thirdly, blindness and aphakia prevalence measures were used to exclude those who were already blind (or had had cataract surgery), so that only the populations at risk of becoming blind were used in computations. Finally, new cases of blindness from congenital cataract were not included in the estimates. The projection for the whole country assumes that the age specific incidence rates in the population of the Arang Block in Central India are fairly similar to the average incidence rates for the country.

At present some 1.2 million cataract extractions are performed in India each year. In spite of this huge effort evidence from recent prevalence data indicates that cataract blindness is increasing (survey conducted by the National Blindness Prevention and Control Programme/World Health Organisation). This has led to a recent suggestion that the ophthalmic services in India should aim to do more than 2 million cataract operations each year. Our findings suggest that the cataract blindness problem in India is too massive to be solved by the surgical programme alone, particularly in view of the aging population trend which is expected substantially to increase the number of new cases of blindness from cataract. Moreover, even under very favourable conditions, cataract surgery is not entirely free of risk. Some of the effort in control of cataract blindness should be directed at developing strategies to reduce the incidence of blinding cataract. Our earlier findings on dehydrational crises as a major risk factor for cataract $^{89}$ offer an opportunity to initiate and test community based interventions to control dehydrational crises and perhaps to control other important risk factors that may be identified through further epidemiological research, thus 
aiming to reduce substantially the number of new cases of cataract blindness that occur each year.

This study was supported by the World Health Organisation's programme for the Prevention of Blindness. The baseline survey was funded by Sight Savers, UK. We thank the research team of Chattisgarh Eye Hospital in Raipur and the consulting ophthalmologist from Switzerland, Dr J-D Verrey, for independent evaluation of the field work.

1 Available data on blindness (Update 1987). World Health Organisation's Programme for the Prevention of Blindness. WHO/PBL/87.14

2 Faal H, Minassian D, Sowa S, Foster A. National survey of blindness and low vision in the Gambia: results. $B r \mathcal{F}$ Ophthalmol 1989; 73: 82-7.

3 Minassian DC, Schemann JF. Prévalence et causes de la cécite au Togo. Unpublished report to Ministry of Health, Republic of Toto, 1987.

4 Negrel AD, Minassian DC. Prévalence et causes de la cécite a las République Populaire du Congo: résultats d'une enquète 1988. Unpublished report to Ministry of Health, People's Republic of the Congo 1988 .

Republic of the Congo 1988 .
5 Negrel AD, Minassian DC, Sayek F. Prevalence and causes of blindness in South Eastern Region of the Republic of Turkey. Unpublished report to Ministry of Health, Republic of Turkey 1989.

6 Mehra V, Minassian DC. A rapid method of grading cataract in epidemiological studies and eye surveys. $\mathrm{Br} \mathcal{F}$ Ophthalmol 1988; 72: 801-3.

7 Miettinen $O$. Estimability and estimation in case-referent studies. Am f Epidemiol 1976; 103: 226-35.

8 Minassian DC, Mehra V, Jones BR. Dehydrational crises from severe diarrhoea or heatstroke and risk of cataract. Lancet 1984; i: 751-3.

9 Minassian DC, Mehra V, Verrey J-D. Dehydrational crises: a major risk factor in blinding cataract. Br f Ophthalmol 1989; 73: $100-5$. 